\section{Cost-effectiveness of prevention strategies for American tegumentary leishmaniasis in Argentina}

\author{
Coste-efectividad de estrategias de prevención \\ contra la leishmaniasis tegumentaria americana \\ en Argentina
}

\author{
Custo-efetividade de estratégias de prevenção \\ contra a leishmaniose tegumentar americana \\ na Argentina
}

Pablo Wenceslao Orellano 1

Nestor Vazquez 2

Oscar Daniel Salomon 1

\footnotetext{
${ }^{1}$ Instituto Nacional de Medicina Tropical, Puerto Iguazu, Argentina.

2 Facultad de Medicina. Universidad de Buenos Aires, Buenos Aires, Argentina.

Correspondence P. W. Orellano Instituto Nacional de Medicina Tropical. Neuquen y Jujuy, Puerto Iguazu, Misiones 3370 Argentina.

porellano@gmail.com
}

\begin{abstract}
The aim of this study was to estimate the cost-effectiveness of reducing tegumentary leishmaniasis transmission using insecticide-impregnated clothing and curtains, and implementing training programs for early diagnosis. A societal perspective was adopted, with outcomes assessed in terms of costs per disability adjusted life years (DALY). Simulation was structured as a Markov model and costs were expressed in American dollars (US\$). The incremental cost-effectiveness ratio of each strategy was calculated. One-way and multivariate sensitivity analyses were performed. The incremental cost-effectiveness ratio for early diagnosis strategy was estimated at US\$ 156.46 per DALY averted, while that of prevention of transmission with insecticide-impregnated curtains and clothing was US\$13,155.52 per $D A L Y$ averted. Both strategies were more sensitive to the natural incidence of leishmaniasis, to the effectiveness of mucocutaneous leishmaniasis treatment and to the cost of each strategy. Prevention of vectorial transmission and early diagnosis have proved to be cost-effective measures.
\end{abstract}

Leishmaniasis; Disease Prevention;

Cost-Effectiveness Evaluation

\section{Resumen}

El objetivo de este estudio fue estimar el costeefectividad de reducir la transmisión de la leishmaniasis tegumentaria americana utilizando ropas y cortinas impregnadas con insecticidas, e implementando programas de entrenamiento para el diagnostico temprano. Se adoptó una perspectiva social, utilizando los años de vida ajustados por discapacidad (AVAD). Se estructuró una simulación con un modelo de Markov. Los costes fueron expresados en dólares americanos (US\$). La razón de coste-efectividad incremental fue calculada para cada estrategia. Se desarrollaron análisis de sensibilidad de una vía y multivariados. La razón de coste-efectividad incremental para el diagnóstico temprano fue estimada en US\$ 156,46 por AVAD evitado, mientras que la razón de coste-efectividad incremental para la prevención con ropa y cortinas impregnadas fue de US\$13.155,52 por AVAD evitado. Ambas estrategias fueron más sensibles a la incidencia natural de leishmaniasis, a la efectividad del tratamiento contra leishmaniasis mucosa y al coste de cada estrategia. La prevención de la transmisión vectorial y el diagnóstico temprano han probado ser medidas coste-efectivas.

Leishmaniasis; Prevención de Enfermedades; Avaliación de Costo-Efectividad 


\section{Introduction}

Leishmaniasis is caused by protozoan parasites of the genus Leishmania (Kinetoplastida: Trypanosomatidae). Leishmania braziliensis is more commonly characterized and associated with outbreaks in Argentina 1. In the New World, the disease is transmitted by the bite of a female phlebotomus of the genus Lutzomyia. Lutzomyia neivai (Lu. intermedia complex), the vector involved in the transmission of leishmaniasis, is one of the species of phlebotomus that is more adapted to habitats modified by human activities in South America. Tegumentary leishmaniasis includes the cutaneous and mucocutaneous clinical forms. Cutaneous leishmaniasis is characterized by the presence of one or more ulcers, which may either heal spontaneously or persist for several months 2 . Mucosal leishmaniasis produces progressive destruction of the nasal septum and palate, causing severe disfigurement of the face and respiratory problems, which do not heal spontaneously 3 . Nowadays, the global incidence of cutaneous leishmaniasis has been estimated at between 0.7 and 1.2 million cases, with an estimated incidence ranging from between 187,200 and 307,800 in the Americas 4 . In Argentina, 150 to 370 cases of cutaneous leishmaniasis are notified per year; the last outbreak was observed in 2002 with 748 human cases throughout the ten endemic provinces 5 . A spatial intervention against the vector in the urban area might have little or no impact in preventing the disease as the transmission occurs mostly in sylvatic contexts. Therefore, early diagnosis and appropriate treatment continue to be the most relevant measures during endemic situations 6. Prevention of transmission in the sylvatic cycle should focus on individual protection with recommendations to avoid humanvector contact in sites abundant with sand flies where transmission risk is high. The use of permethrin-impregnated military uniforms and the possibility of combination with repellents have been evaluated in Iran and Colombia 7,8,9. So far, according to the articles cited, the use of impregnated clothing has presented variable efficacy to prevent leishmaniasis. However, based on the results presented in two of these articles, the effectiveness would be around $70 \%$, considering either case prevention or biting protection. In Argentina, insecticide-treated curtains in homes and the use of insecticide-impregnated clothing in subjects working in wild environments could have great potential for the prevention of leishmaniasis. On the other hand, early diagnosis allows rapid treatment and could contribute to therapeutic success. This may be achieved by training physicians working in primary care centers and healthcare providers collaborating in active recruitment of cases. A proper identification, diagnosis and treatment of cutaneous leishmaniasis are important due to the risk of developing the mucocutaneous clinical form, concomitantly or after disease remission 10 . Early diagnosis and referral for timely treatment of patients with mucocutaneous leishmaniasis has been proposed as an important strategic approach to the disease by national programs for the management of this condition, and by nongovernmental organizations 11 . There are, to the authors' knowledge, no published studies of the effectiveness of this strategy.

The goal of our study is to estimate the costeffectiveness of implementing two strategies for the prevention of leishmaniasis in endemic areas of Argentina: reducing disease transmission using insecticide-impregnated clothing and curtains and implementing training programs for early diagnosis.

\section{Methods}

\section{Study design}

A cost-effectiveness evaluation was conducted from a societal perspective, considering direct and indirect costs. A government perspective was also adopted for the base-case analysis in order to provide elements of comparison. The time frame and analytic horizon considered included the lifetime of persons at risk for leishmaniasis, assuming that each strategy would be in place for the entire period. The disability adjusted life years (DALY) for tegumentary leishmaniasis were used as measure of effectiveness. Two strategies were evaluated separately. First, prevention of transmission with pyrethroidtreated clothing for rural workers exposed to risk and curtains impregnated with the insecticide in houses in endemic areas, corresponding to three major ecoregions of northern Argentina: subtropical forest Yungas, dry and humid Chaco, and Paranaense forest 12 . These ecoregions include nine Argentinian provinces: Salta, Jujuy, Tucumán, Catamarca, Formosa, Chaco, Santiago del Estero, Misiones and Corrientes. Second, implementation of training reinforcement programs to improve early diagnosis of patients and timely treatment. These strategies were compared with the original strategic approach to the disease, which consists of diagnosis and treatment of the cases detected (passive detection), without taking preventive measures against transmission. 


\section{Model overview}

Simulation was structured as a Markov model in 1-year cycles in a cohort of 100,000 inhabitants from birth to the age of 85 years in areas of Argentina with active disease transmission. The values of cost, effectiveness and transition probabilities parameters were collected during 2010. Five health states were considered for the dynamics of tegumentary leishmaniasis: susceptible, person with cutaneous leishmaniasis, person with mucocutaneous leishmaniasis, person with mucocutaneous leishmaniasis not treated, and deceased (Figure 1). Treatments with firstand second-line drugs were considered intermediate transitional states because they involved less time. The cohort mortality was calculated from data of the National Census and Statistics Institute 13 and National Ministry of Health of Argentina 14 for the year 2010. A specific mortality or reduction in life expectancy was not assumed for patients with leishmaniasis, due to the absence of notifications of deaths related to mucosal leishmaniasis in Argentina (data from the National Reference Laboratory). The transition probabilities incorporated in the model were obtained from bibliographic references (Table 1). The extreme values of the intervals were considered for different values of transition probabilities according to the publications. The median of all values was calculated to obtain the baseline. In the absence of bibliographic references, the

Figure 1

Markov model of tegumentary leishmaniasis infection and treatment.

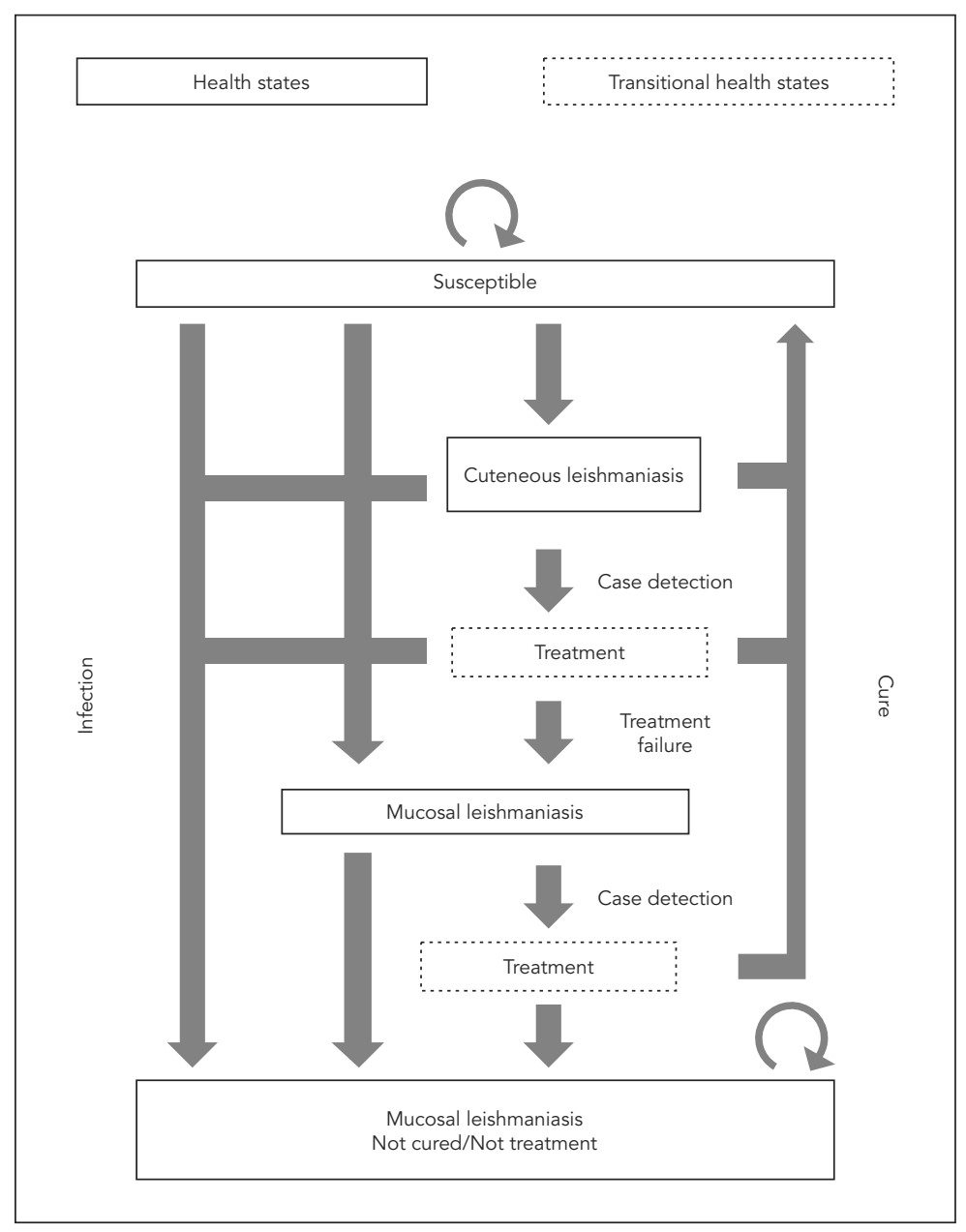


Table 1

Transition probabilities of the Markov model. Parameter values and ranges.

\begin{tabular}{|c|c|c|c|c|c|}
\hline Probabilities & Strategy & Baseline & Ranges & Distribution & Reference \\
\hline $\begin{array}{l}\text { Anual incidence of cutaneous } \\
\text { leishmaniasis ( } \times 100,000 \\
\text { inhabitants) }\end{array}$ & Original and early diagnosis & 25.8 & $7.8-128.6$ & Triangular & Salomón et al. 36 \\
\hline $\begin{array}{l}\text { Percentage of cutaneous } \\
\text { leishmaniasis detection }\end{array}$ & $\begin{array}{c}\text { Original and transmission } \\
\text { prevention }\end{array}$ & 93.4 & $90.9-95.9$ & Triangular & Salomón et al. 15,16 \\
\hline $\begin{array}{l}\text { Percentage of mucosal } \\
\text { leishmaniasis detection }\end{array}$ & All & 100.0 & - & - & Assumed \\
\hline $\begin{array}{l}\text { Percentage of cutaneous } \\
\text { leishmaniasis detection }\end{array}$ & Early diagnosis & 99.0 & $96.0-100.0$ & Triangular & Assumed \\
\hline $\begin{array}{l}\text { Percentege of effectiveness } \\
\text { of meglumine antimoniate for } \\
\text { cutaneous leishmaniasis }\end{array}$ & All & 82.0 & $42.0-100.0$ & Triangular & $\begin{array}{l}\text { Deps et al. } 37 \text {; Passos et al. } 38 \text {; Paula } \\
\text { et al. } 39 \text {; Oliveira-Neto et al. } 40 \text {; } \\
\text { Krolewiecki et al. } 41 \text {; Teixeira et al. }{ }^{42} \text {; } \\
\quad \text { Nilforoushzadeh et al. } 43\end{array}$ \\
\hline $\begin{array}{l}\text { Probability of mucosal } \\
\text { presentation }\end{array}$ & All & 0.03 & - & - & Lessa et al. 10 \\
\hline $\begin{array}{l}\text { Percentage of effectiveness } \\
\text { of meglumine antimoniate for } \\
\text { mucosal leishmaniasis }\end{array}$ & All & 91.0 & $70.0-100.0$ & Triangular & $\begin{array}{c}\text { Zajtchuk et al. 44; Martins Netto et al. } \\
\text { 45; Oliveira-Neto et al. } 46\end{array}$ \\
\hline $\begin{array}{l}\text { Percentage of effectiveness } \\
\text { of amphotericin B for mucosal } \\
\text { leishmaniasis }\end{array}$ & All & 88.0 & $80.0-90.0$ & Triangular & $\begin{array}{c}\text { Dedet et al. } 47 \text {; Vlada Rodriguez et } \\
\text { al. } 48\end{array}$ \\
\hline $\begin{array}{l}\text { Percentage of effectiveness of } \\
\text { transmission prevention }\end{array}$ & Transmission prevention & 60.0 & $40.0-80.0$ & Triangular & Reyburn et al. 49 \\
\hline
\end{tabular}

transition probability was assumed. The probability of being diagnosed with cutaneous leishmaniasis was estimated based on the results of two investigations made on two outbreaks in the provinces of Tucuman and Misiones, northern Argentina, during 2003 and 2004 15,16 (unpublished data used for the estimation). The probability of being diagnosed was assumed unchanged during interepidemic periods, given that the surveillance system was maintained active through local training and periodic evaluation after these investigations. The assumptions of the model transition probabilities were the following: (1) the probability of presenting the mucocutaneous form was considered independent of having presented the cutaneous form before and of having received treatment; this was proposed as the most conservative scenario for the presented model, given that mucosal leishmaniasis may occur at the same time as cutaneous leishmaniasis 17; (2) a patient with untreated mucocutaneous form suffers the consequences of reduced quality of life throughout his/her lifetime; and (3) the probability of relapse of the cutaneous form after failed treatment was not considered. An expert panel of two infectious diseases clinicians and three epidemiologist, members of the National Leishmaniasis Control Programme, validated the estimates and assumptions used in this model. The simulation model was developed using the Decision Analysis software by Tree Age (TreeAge Software Inc., Williamstown, USA), version 2007.

\section{Costs}

Direct and indirect costs were evaluated. The monetary values of intangible costs were not considered, as they were included within the health outcomes. Direct costs of healthcare included medical costs, days of hospitalization, laboratory tests (complete blood count, liver panel, serum creatinine, serum amylase and electrolytes), electrocardiogram, medications administered and subsequent evaluation of patients after treatment. Costs of meglumine antimoniate were communicated by the National Ministry of Health, which provides medication to patients treated in all public and private healthcare centers of the country. Indirect costs per workdays lost were estimated from data of the Argentinian 
Ministry of Labour. Direct costs of insecticides to be applied in curtains and work clothing were considered for the prevention of transmission strategy. In a wide range of scenarios, the indirect costs of buying curtains for the houses and the indirect cost of the time required to apply the insecticide were considered. Market values were used to estimate insecticide costs.

Costs of training included direct costs of teachers' salaries and subsistence expenses and indirect costs of transport allowances for teachers and students, meals and accommodation and working days lost. Training programs were applied to 20 participants and each course had two teachers. One physician was trained in cities with populations above 2,000 inhabitants, whereas five physicians were trained when the population was above 100,000 inhabitants. The parameters used are described in Table 2 with their upper and lower ranges, distribution and source of information. A micro-costing approach was used for estimating costs 18 . This method is especially useful for estimating the cost of new interventions, for producing estimates in studies that include non-market goods, and for studying within-procedure cost variation ${ }^{19}$. All costs were expressed in 2010 American dollars (US\$).

\section{Health outcomes}

Effectiveness was calculated as DALY averted, estimated in the study of global burden of diseases by Murray \& Lopez 20 for cutaneous leishmaniasis. There are no estimations available about DALY associated with mucocutaneous leishmaniasis. Therefore, we used the value associated with the disability produced by leprosy. Both conditions display similar spectra of disease phenotypes, which are dependent on $\mathrm{T}$ cell-mediated immunity 21 and produce similar symptoms as those seen in nasal mucosa 22,23,24. The use of this disability weight was mentioned by Reithinger \& Coleman 25 in their investigation on cost effectiveness of an operational program

Table 2

Costs for treatment of patients, early diagnosis and prevention strategies.

\begin{tabular}{|c|c|c|c|c|}
\hline Costs * & Strategy & Baseline & Ranges & Distribution \\
\hline $\begin{array}{l}\text { Treatment of cutaneous leishmaniasis with meglumine } \\
\text { antimoniate }\end{array}$ & All & & - & - \\
\hline Medical costs ** & & 47.70 & & \\
\hline Work days lost $* * \star$ & & 446.10 & & \\
\hline Total & & 493.80 & & \\
\hline Treatment of mucosal leishmaniasis with meglumine antimoniate & All & & - & - \\
\hline Medical costs ** & & 60.97 & & \\
\hline Work days lost $* * *$ & & 594.80 & & \\
\hline Total & & 655.77 & & \\
\hline $\begin{array}{l}\text { Treatment of mucosal leishmaniasis with amphotericin b } \\
\text { deoxycholate }\end{array}$ & All & & - & - \\
\hline Medical costs ** & & $3,435.57$ & & \\
\hline Work days lost $* * *$ & & $1,487.00$ & & \\
\hline Total & & $4,922.56$ & & \\
\hline Work days lost due to mucosal leishmaniasis \# & All & 764.74 & $0.00-7,647.42$ & Triangular \\
\hline Costs of transmission prevention \#\# & Transmission prevention & 0.94 & $0.44-3.55$ & Triangular \\
\hline Costs of early diagnosis \#\#\# & Early diagnosis & 0.02 & $0.01-0.04$ & Triangular \\
\hline
\end{tabular}

* All cost are expressed in 2010 US dollars:

** Medical costs include medical examinations, electrocardiogram, laboratory tests and drugs;

*** Work days lost for treatment, estimated according to the average wage of Argentinean salaried workers in 2011;

\# Work days lost due to disfiguring lesions after the infection heals, considering $10 \%$ work-capacity reduction (baseline), without work-capacity reduction and $100 \%$ work-capacity reduction (ranges);

\#\# Including permethrin (insecticide) for clothing, curtains and insecticide application (baseline), insecticide without application (lower range) and insecticide plus application and curtains purchase, once a year (upper range);

\#\# Costs of training for early diagnosis include teachers' salaries and allowance, per diems, mobility and organizational costs for courses occurring every two years (baseline), every five years (lower range) or once a year (upper range). 
for leishmaniasis treatment. In this article, the authors discuss the disability weighting for cutaneous leishmaniasis as set by the Global Burden of Disease Study 20, and the possibility of using a disability weight similar to a cleft lip, bancroftian filariasis or debilitating leprosy. The standardized disability weights for cutaneous leishmaniasis (0.023) and for mucosal leishmaniasis (0.152) were multiplied by the duration of each condition and estimated in 0.25 years ( 3 months) for cutaneous leishmaniasis and 0.5 years ( 6 months) for mucosal leishmaniasis 2 . DALY were not adjusted by age due to the small impact of the age-weight function 26 .

\section{Temporal effects}

For the base-case, both effectiveness and cost were discounted at $3 \%$, considering an interval from $1 \%$ to $5 \%$ in the sensitivity analysis. Inflation in Argentina for 10 years was considered for analyzing the temporal effect of costs (7.44\%).

\section{Cost-effectiveness analysis}

The incremental cost-effectiveness ratio of each strategy (US\$/DALY) was calculated to compare the results with other studies. This ratio represents the cost required to avert one DALY. A lower incremental cost-effectiveness ratio value implies a better cost-effectiveness. The strategies were considered highly cost-effective if the incremental cost-effectiveness ratio value per DALY averted was less than the gross domestic product per capita (GDP) of the country, and cost-effective between one and three times GDP per capita according to the recommendations of the World Health Organization 27.

\section{Sensitivity analysis}

Sensitivity analysis was used for evaluating uncertainty in the structure of the model, the parameters estimated and the assumptions. Each key parameter was sequentially tested in a oneway sensitivity analysis using a tornado analysis. A multivariate, probabilistic sensitivity analysis based on 10,000 Monte Carlo simulations was performed to estimate the effect of simultaneous variability of the parameters involved in the results of the model. The values of parameters within the range were assumed to follow a triangular distribution. The outcome variable was assumed normally distributed 28 . Based on the results of the Monte Carlo simulations for each strategy, the incremental cost-effectiveness analysis was calculated using the cost-effectiveness plane 29 , with the incremental effectiveness on the $\mathrm{x}$-axis and the incremental cost on the y-axis. The acceptability curve, which represents the probability that the intervention is acceptable given varying thresholds of inversion, was analyzed from Argentina's GDP to a value 10 times greater.

\section{Results}

\section{Health impact}

The incidence of cutaneous leishmaniasis and mucocutaneous leishmaniasis in the absence of prevention of transmission would be 2,061 and 526 cases per 100,000 inhabitants, respectively. Using insecticide-impregnated curtains and clothing, the incidence of cutaneous leishmaniasis and mucocutaneous leishmaniasis would be reduced by 2.5 times ( 825 cases per 100,000 inhabitants) and by 3 times (174 cases per 100,000 inhabitants), respectively. Implementing this strategy would prevent 220.71 DALY per 100,000 inhabitants. Training healthcare workers in early diagnosis would prevent 170.63 DALY per 100,000 inhabitants, without reduction in the number of cases. However, the incidence of cutaneous and mucocutaneous leishmaniasis would not be affected, as this strategy is not focused on reducing disease transmission.

\section{Cost-effectiveness analysis}

From the societal perspective, a cost of US\$ $252,790.39$ was estimated for the cohort of 100,000 inhabitants in the treatment strategy. The cost rises to US\$259,056.51 when training strategies for early diagnosis are performed. The prevention of transmission approach increased the cost to US\$990,288.44. The incremental costeffectiveness ratio for early diagnosis strategy was estimated at US\$156.46 per DALY averted, while that of prevention of transmission with insecticide-impregnated curtains and clothing was US\$ 13,155.52 per DALY averted. Based on Argentina's GDP per capita for the year 2010 (US\$9,067), the early diagnosis strategy would be highly costeffective (less than the GDP per capita), while the prevention of transmission strategy would be cost-effective (less than three times the GDP per capita). Considering the government perspective (without accounting for social costs), the incremental cost-effectiveness ratio for early diagnosis strategy was US\$ 459.10 per DALY averted, and the incremental cost-effectiveness ratio of prevention with insecticide was US\$ 16,478.13 per DALY averted. From this perspective, both strategies remain cost-effective. 


\section{Sensitivity analysis}

The results of univariate analysis in both strategies were more sensitive to the natural incidence of cutaneous leishmaniasis, to the effectiveness of mucosal leishmaniasis treatment with firstline drug and to the cost of each strategy (Figures 2 and 3). The results showed that the effectiveness of the strategies had little influence.

For the early diagnosis strategy, the costeffectiveness plane that represents the 10,000 Monte Carlo simulations of the cost-effectiveness ratio demonstrates a certain degree of uncertainty (Figure 4). Most simulations were located in the northwest quadrant $(52.29 \%)$ and northeast quadrant $(43.63 \%)$ which means that in $95.92 \%$ of the simulations the early diagnosis strategy was more costly than the original strategy. In turn, the strategy was more effective in $47.71 \%$ of simulations. For the prevention of disease transmission strategy, most of the simulations were located in the northeast quadrant $(89.52 \%)$, indicating that the strategy was more effective and more costly (Figure 4). The absence of simulations in the southwest and southeast quadrants indicated that, in all simulations, the cost of the prevention of transmission strategy was higher than that of the original strategy.

The acceptability curves for incremental cost-effectiveness ratio are presented in Figure 5 . For the early diagnosis strategy, in $21 \%$ of the simulations the incremental cost-effectiveness ratio was below the threshold GDP per capita and in $34 \%$ the incremental cost-effectiveness ratio was less than three times the GDP per capita. Even if the threshold GDP per capita is increased 10 times, the percentage of simulations of incremental cost-effectiveness ratio below that value is not beyond $43 \%$. For the prevention of transmission strategy, less than $1 \%$ of simulations are below the threshold GDP per capita. When the threshold GDP per capita is increased three times, the percentage of simulations below that value is of $25 \%$. If the threshold is increased 10 times, the percentage of simulations is $75 \%$.

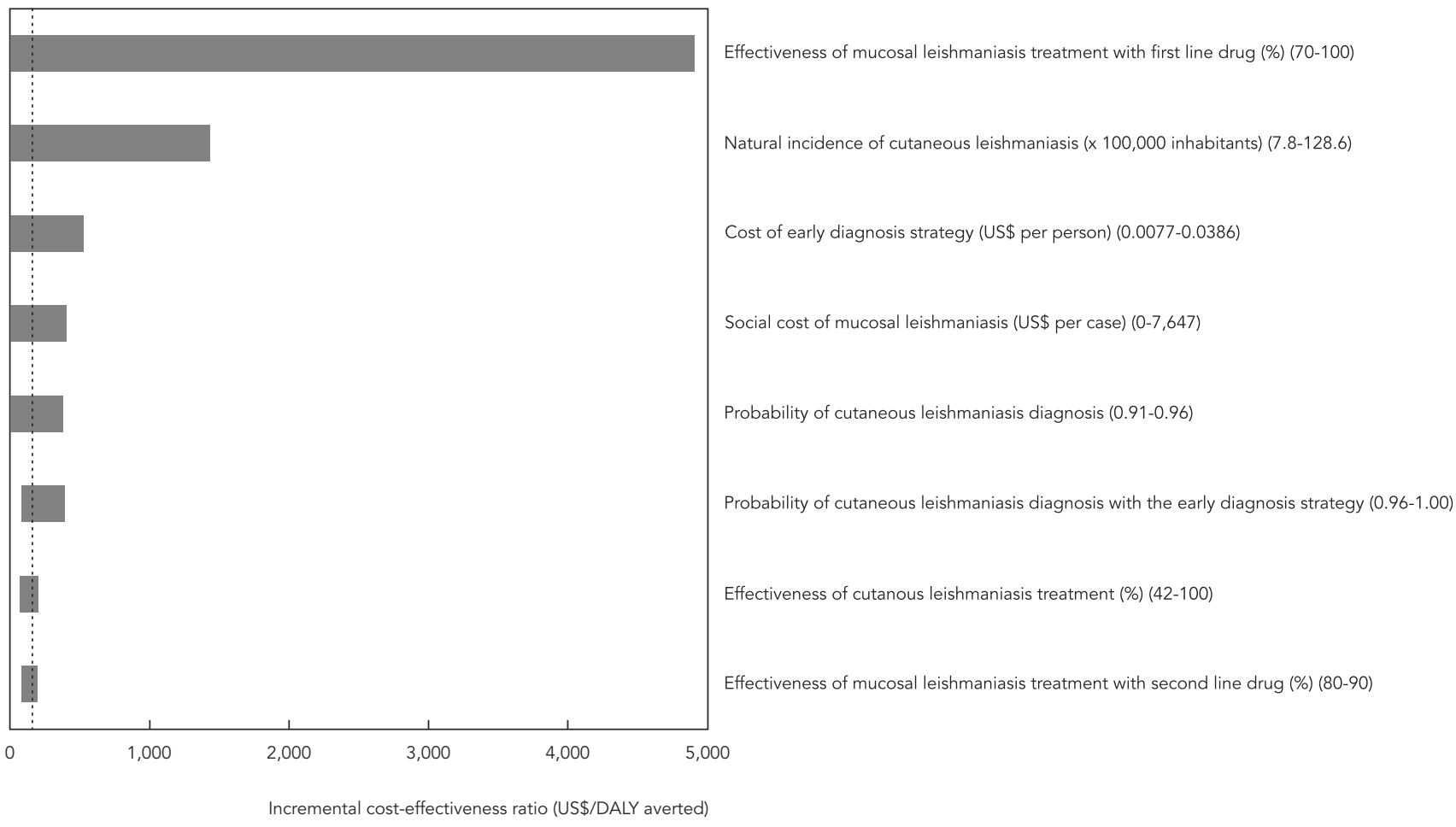


Figure 3

One-way sensitivity analysis of transmission prevention strategy

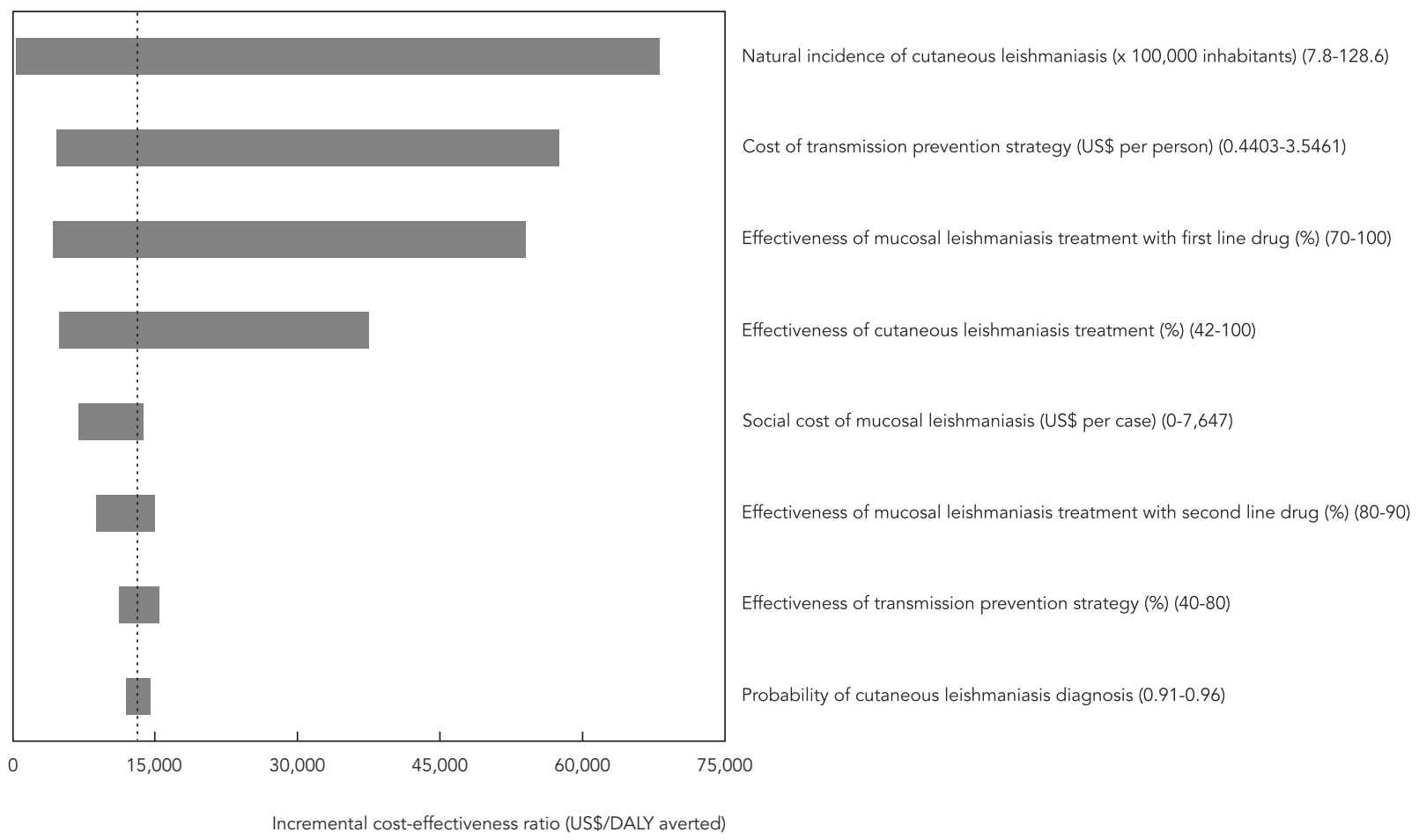

\section{Discussion}

The transmission cycle of tegumentary leishmaniasis depends on complex parameters that are difficult to estimate. The variety of factors taking place (environmental and social factors, among others) determines the complexity of the processes involved which, in turn, hinders the development of the models. Up to the present time, cost-effectiveness studies have focused on analyzing alternative treatments for patients with new drugs available on the market. Tertiary prevention studies of the disease (treatment) can simplify the models. These studies focus on patients already detected by the healthcare system; thus, they are not obliged to consider those parameters that have any influence in the transmission and diagnosis of the disease. This study does not evaluate the efficiency of treatments but applies those currently used by disease control programs in Latin America. On the contrary, this study is focused on primary and secondary prevention. Firstly, primary prevention is accomplished by prevention of transmission through insecticide-impregnated clothing and curtains. Secondly, secondary prevention is evaluated by training healthcare professionals in early diagnosis of cases of mucocutaneous leishmaniasis.

Prevention of transmission strategies are not currently used in Argentina. Few studies have reported the experience with fumigations in Latin America and results have been diverse. Probably the sylvatic component of disease transmission might have determined the lack of success of these methods. Therefore, for the effectiveness of this strategy in the model a wide range for the parameter was considered, while the cost values could be more accurate. According to the results of this model, this strategy might reduce the incidence of leishmaniasis by 2.5 to three times, indicating a significant reduction of DALY associated with this disease in the population. Using this strategy, the estimated reduction of mucosal leishmaniasis is similar to the reduction of cutaneous leishmaniasis. This effect on mucocutaneous leishmaniasis is not common after applying antivectorial measures due to the long incubation period and to the development 


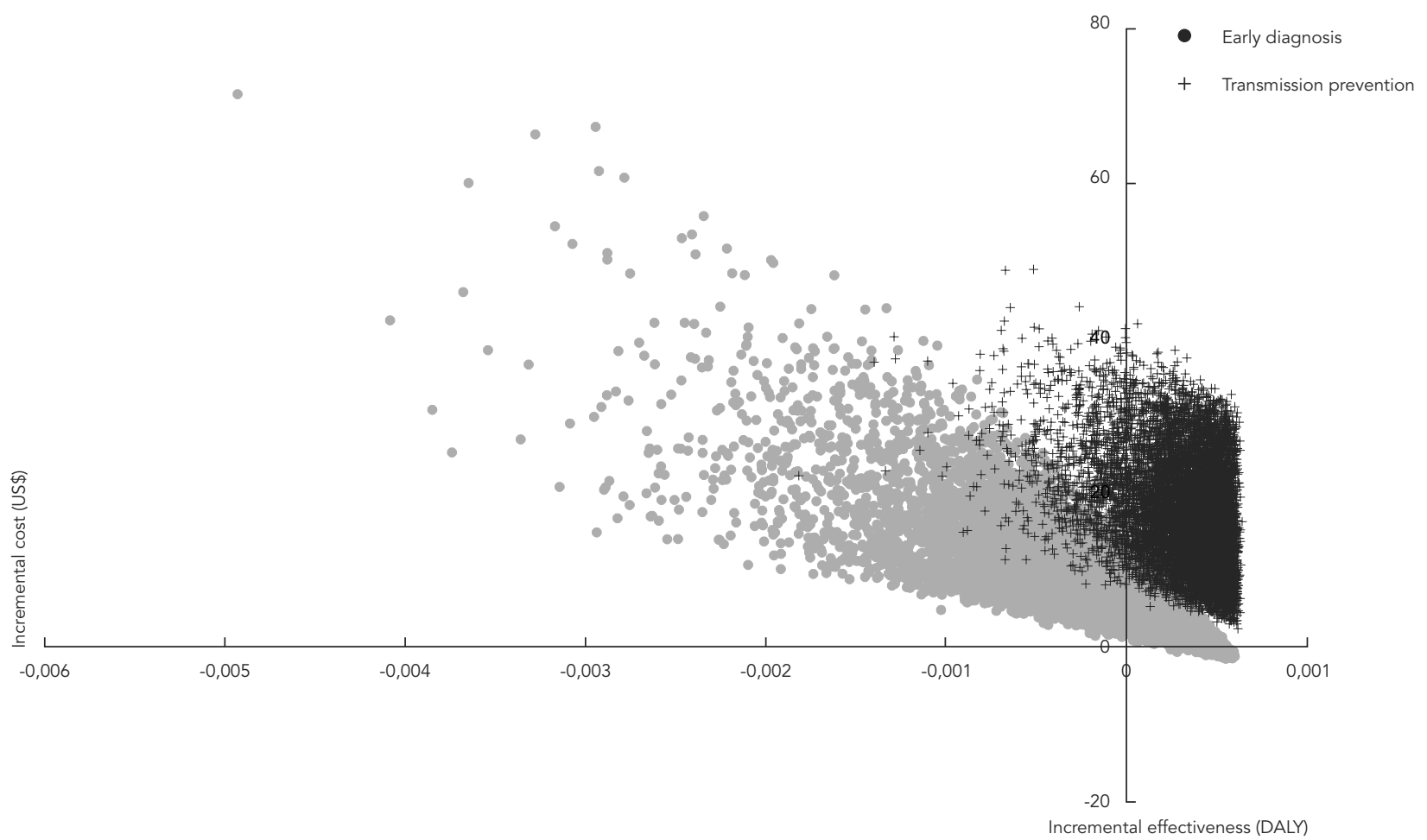

of mucocutaneous forms secondary to cases of cutaneous leishmaniasis. On the contrary, the incidence of mucocutaneous forms usually increases during interepidemic periods because of previous epidemic outbreaks of cutaneous leishmaniasis. However, the fact that this study evaluates a cohort of persons throughout their lifetime should be taken into account, so the reductions in the incidence of mucocutaneous leishmaniasis may be estimated by the end of this long period evaluated. The estimated incremental cost-effectiveness ratio is less than three times the GDP per capita (US\$ 9,067.00 for the year 2010) for both perspectives; thus, this strategy is considered cost-effective according to the criterion of the World Health Organization (WHO). The sensitivity analysis indicated a high dependence on the natural incidence of the disease, demonstrating that prevention of transmission strategies are more efficient in the worst endemic scenarios. The cost of applying the strategy also showed an important dependence. In addition, the Monte Carlo analysis re- vealed that $100 \%$ of the simulations were more costly compared to the treatment strategy currently used. These costs include costs of buying curtains, clothing and insecticide and costs of applying the insecticide, which may be reduced as time goes by after implementing the strategy. The acceptability curve shows that $75 \%$ of the simulations are considered cost-effective after adopting an acceptability threshold equivalent to 10 times the GDP per capita. Apart from the costs, this strategy has a significant implication, as the possibility of cooperation among municipal, provincial and national governments and non-governmental organizations to generate small self-sustaining entrepreneurship. These mechanisms would allow maintaining this strategy with minimal costs for the population for a long-term period. The money saved could be accompanied by community empowerment in order to manage community problems and find ways to solve them. Yet, the acceptability of the strategies proposed by the population should always be considered. 
Cost-effectiveness acceptability curves, showing the probabilities of each strategy being cost-effective considering incrementals cost-effectiveness threshold ratios.

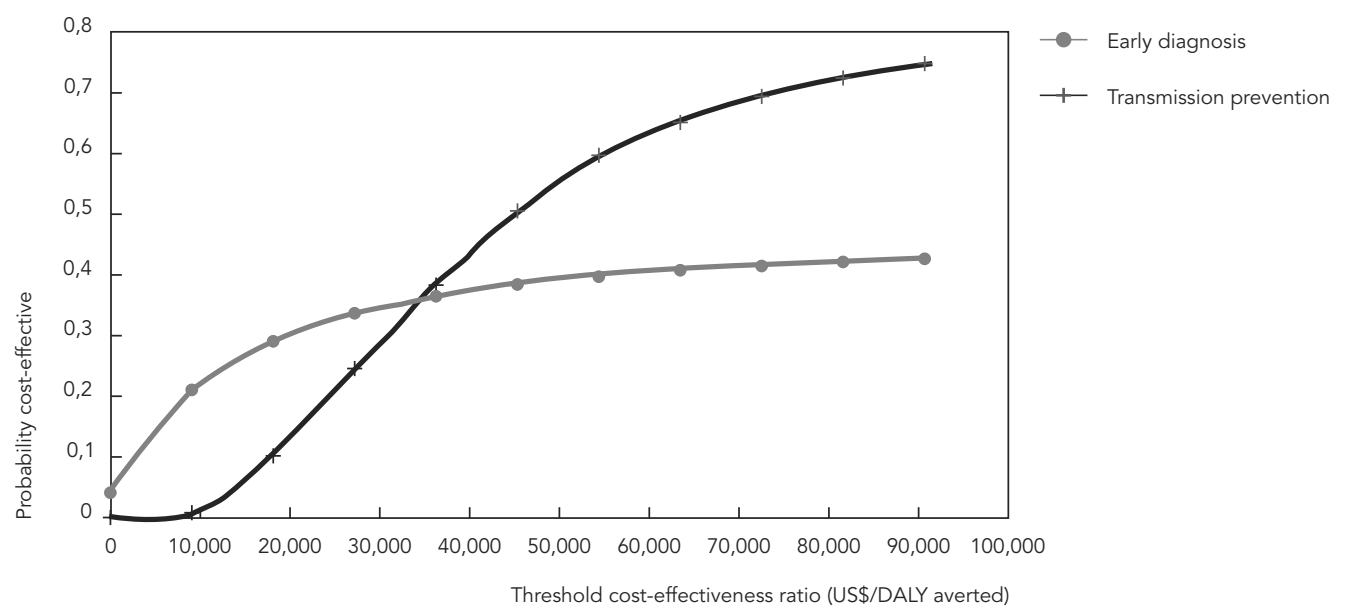

Training healthcare agents in recognizing clinical symptoms to improve the early diagnosis strategy was a highly cost-effective approach, with a lower incremental cost-effectiveness ratio than the GDP per capita for both perspectives. The use of this strategy would not reduce the incidence of cutaneous or mucosal leishmaniasis, yet it would improve timely treatment of cases, contributing to the therapeutic success. The cutaneous form of the disease does not produce a significant reduction in the quality of life, is usually painless and the lesion disappears within a few months, even in the absence of treatment. However, the disease may produce psychological and social after-effects that may generate transient disability or loss in working days. The sensitivity analysis demonstrated that the parameters that had more influence in the outcomes of the model were strategy-related costs and costs associated with the disease, the incidence and the probability of making a diagnosis in the current situation. In a study performed in the north of the country, the percentage of under-reporting of cutaneous leishmaniasis was approximately $50 \%$, emphasizing the importance of the training strategy for early diagnosis ${ }^{30}$. The Monte Carlo method showed a significant variability in the results of the simulations. The strategy was dominant at baseline; yet, only $48 \%$ of the simulations presented positive incremental effectiveness when compared with the original strategy. This would indicate that the range considered in the parameters had a significant influence and would demonstrate the sensitivity of the model. In turn, the acceptability curve shows that only $43 \%$ of the simulations were cost-effective even after adopting an acceptability threshold equivalent to 10 times the GDP per capita. Special attention should be paid to costs and effectiveness before implementing this strategy in order to reduce outcome variables dispersion. In endemic areas of visceral leishmaniasis and malaria, active case detection is a valuable strategy to improve patients' therapeutic expectations and community-based disease management $31,32,33$. A study performed in the Gran Chaco Region in Argentina about Chagas disease demonstrated that active case detection might contribute to increase impact, cost-effectiveness and public acceptance 34 . The present study did not evaluate the implementation of an active case detection system but the capability of the healthcare system for passive case detection. Active case detection by healthcare agents making regular revisions of housings would be more effective than passive detection. However, the implementation of a home visiting system in places without an established structure of healthcare agents might be excessively costly. In this sense, the implementation of mixed strategies by neighborhood-based health promoters, community health leaders and other 
community actors (NGOs, the church, schools) might reduce costs.

This study presents some limitations. Firstly, the values of some transition probabilities between health states were based on direct evidences of the present study or bibliographic references, while other values were assumed and thus were less supported by facts. This is due to the lack of studies analyzing the effective measures to prevent vectorial transmission and of strategies for early diagnosis of cases. For this reason, parameters with wide ranges were considered to cover uncertainties and thus perform a most conservative analysis. Secondly, simplifications were made to prevent the mathematical model from becoming excessively complex. This happened, for example, with the assumption that a person treated with mucocutaneous leishmaniasis would keep on suffering the negative aftereffects of the disease throughout his/her lifetime. This assumption does not consider the possibility of performing reconstructive surgeries. Other example of simplification was that the probability of relapse of the cutaneous form after failed treatment was not considered. The estimation of costs was also simplified. Although attempts were made to consider the most relevant costs associated with each strategy in all scenarios, capital costs and depreciation of capital assets, since purchase of laboratory equipment, hospital or healthcare center infrastructure costs were not included. Finally, as there were no estimations available about the DALY associated with mucocutaneous leishmaniasis, we used the value associated with the disability produced by leprosy, as both conditions have similar clinical presentation and are regularly confused 22,23,24. Changing the health outcome could have led to mistakes in the value of DALY associated with mucocutaneous leishmaniasis. The use of DALY associated with cutaneous mucosal tertiary syphilis would have been another option, with even greater reductions in DALY values 35 .

In conclusion, this study underlines the importance of primary and secondary prevention strategies for the approach to tegumentary leishmaniasis. In the first place, early diagnosis achieved by training healthcare agents is a highly cost-effective measure, with an incremental costeffectiveness ratio of US\$156.56, and prevention of vectorial transmission is an effective measure, with an incremental cost-effectiveness ratio of US\$ $13,155.52$, compared to the original strategy. These results should be complemented with more precise studies evaluating the effectiveness of the methods proposed in order to achieve more adjusted cost-effectiveness estimates.

\section{Resumo}

O objetivo deste estudo foi estimar o custo-efetividade para reduzir a transmissão da leishmaniose tegumentar americana, utilizando roupas e cortinas impregnadas com inseticidas e implementando programas de treinamento para o diagnóstico precoce. Adotou-se uma perspectiva social, usando os anos de vida ajustados por incapacidade (AVAI). Estruturou-se uma simulação com o modelo de Markov. Os custos foram expressos em US\$. A taxa de custo-efetividade incremental foi calculada para cada estratégia. Foi desenvolvida análise de sensibilidade, uni e multivariada. A taxa de custoefetividade incremental para o diagnóstico precoce foi estimada em US\$156,46 por AVAI evitado, enquanto a taxa para prevenção com roupas e cortinas impregnadas foi de US\$13.155,53 por AVAI evitado. Ambas as estratégias foram mais sensíveis à incidência natural de leishmaniose, à efetividade do tratamento contra a leishmaniose mucocutânea e ao custo de cada estratégia. A prevenção da transmissão vetorial e o diagnóstico precoce provaram ser medidas custo-efetivos.

Leishmaniose; Prevenção de Doenças; Avaliação de Custo-Efetividade 


\section{Contributors}

P. W. Orellano worked on the study design, data collection, analysis of results and study write-up. N. Vazquez worked on the study design, analysis of results and revisión of the final version of the text. O. D. Salomon worked on the study design, results analysis, as well as overseeing the write-up.

\section{Acknowledgments}

To Sergio Sosa Estani, Christian Hertlein, Julieta Reynoso (Ministerio de Salud de la Nación), Tomas Orduna (Hospital de Infecciosas F. Muñiz) and Andrea Mastrangelo (CONICET), for their useful comments.

\section{References}

1. Córdoba Lanus E, Salomón OD. Phlebotominae fauna in the province of Tucumán, Argentina. Rev Inst Med Trop São Paulo 2002; 44:23-7.

2. Goto H, Lindoso JA. Current diagnosis and treatment of cutaneous and mucocutaneous leishmaniasis. Expert Rev Anti Infect Ther 2010; 8:419-33.

3. Amato VS, Tuon FF, Siqueira AM, Nicodemo AC, Amato Neto V. Treatment of mucosal leishmaniasis in Latin America: systematic review. Am J Trop Med Hyg 2007; 77:266-74.

4. Alvar J, Vélez ID, Bern C, Herrero M, Desjeux P, Cano J, et al. Leishmaniasis worldwide and global estimates of its incidence. PLoS One 2012; 7:e35671.

5. Salomón OD, Quintana MG, Mastrángelo AV, Fernández MS. Leishmaniasis and climate change-case study: Argentina. J Trop Med 2012; 2012:601242.

6. Salomón OD, Pascual MB, Molinari ML, Verri V. Study of a cutaneous leishmaniasis outbreak in General Vedia, Province of Chaco, 1996. Rev Inst Med Trop São Paulo 2001; 43:99-104.
7. Soto J, Medina F, Dember N, Berman J. Efficacy of permethrin-impregnated uniforms in the prevention of malaria and leishmaniasis in Colombian soldiers. Clin Infect Dis 1995; 21:599-602.

8. Asilian A, Sadeghinia A, Shariati F, Jome MI, Ghoddusi A. Efficacy of permethrin-impregnated uniforms in the prevention of cutaneous leishmaniasis in Iranian soldiers. J Clin Pharm Ther 2003; 28:175-8.

9. Koobdel M. Evaluation of permethrin treated clothing for personal protection against Phlebotomus papatasi (Diptera: Psychodidae). Journal of Entomology 2008; 5:51-5.

10. Lessa MM, Lessa HA, Castro TW, Oliveira A, Scherifer A, Machado P, et al. Mucosal leishmaniasis: epidemiological and clinical aspects. Rev Bras Otorrinolaringol 2007; 73:843-7.

11. Rojas CA. An ecosystem approach to human health and the prevention of cutaneous leishmaniasis in Tumaco, Colombia. Cad Saúde Pública 2001; 17 Suppl:193-200. 
12. Quintana MG, Fernández MS, Salomón OD. Distribution and abundance of phlebotominae, vectors of leishmaniasis, in Argentina: spatial and temporal analysis at different scales. J Trop Med 2012; 2012:652803.

13. Instituto Nacional de Estadísticas y Censos. Estimaciones y proyecciones de población. Total del país, 1950-2015: población por sexo y grupos quinquenales de edad. http://www.indec.gov.ar (accessed on 08/Dec/2011).

14. Dirección de Estadísticas e Información de Salud, Secretaria de Políticas, Regulación e Institutos, Ministerio de Salud de la Nación. Estadísticas vitales: información básica, año 2010. Buenos Aires: Dirección de Estadísticas e Información de Salud Secretaria de Políticas, Regulación e Institutos, Ministerio de Salud de la Nación; 2011.

15. Salomón OD, Quintana MG, Flores I, Andina AM, Molina S, Montivero L, et al. Phlebotominae sand flies associated with a tegumentary leishmaniasis outbreak, Tucumán Province, Argentina. Rev Soc Bras Med Trop 2006; 39:341-6.

16. Salomón OD, Acardi SA, Liotta DJ, Fernández MS, Lestani E, López D, et al. Epidemiological aspects of cutaneous leishmaniasis in the Iguazú falls area of Argentina. Acta Trop 2009; 109:5-11.

17. Boaventura VS, Cafe V, Costa J, Oliveira F, Bafica A, Rosato A, et al. Concomitant early mucosal and cutaneous leishmaniasis in Brazil. Am J Trop Med Hyg 2006; 75:267-9.

18. Rice DP. Estimating the cost of illness. Am J Public Health Nations Health 1967; 57:424-40.

19. Frick KD. Micro-costing quantity data collection methods. Med Care 2009; 47:76-81.

20. Murray CJL, Lopez AD. The global burden of disease. v. 1. Cambridge: Harvard University Press; 1996.

21. Matos DS, Azeredo-Coutinho RB, Schubach A, Conceição-Silva F, Baptista C, Moreira JS, et al. Differential interferon- gamma production characterizes the cytokine responses to Leishmania and Mycobacterium leprae antigens in concomitant mucocutaneous leishmaniasis and lepromatous leprosy. Clin Infect Dis 2005; 40:5-12.

22. Goulart IM, Patrocínio LG, Nishioka SA, Patrocínio JA, Ferreira MS, Fleury RN. Concurrent leprosy and leishmaniasis with mucosal involvement. Lepr Rev 2002; 73:283-4.

23. Singh S. New developments in diagnosis of leishmaniasis. Indian J Med Res 2006; 123:311-30.

24. Dassoni F, Abebe Z, Naafs B, Morrone A. Cutaneous and mucocutaneous leishmaniasis resembling borderline-tuberculoid leprosy: a new clinical presentation. Acta Derm Venereol 2013; 93:74-7.

25. Reithinger R, Coleman PG. Treating cutaneous leishmaniasis patients in Kabul, Afghanistan: costeffectiveness of an operational program in a complex emergency setting. BMC Infect Dis 2007; 7:3.

26. Barendregt JJ, Bonneux L, van der Maas PJ. DALYs: the age-weights on balance. Bull World Health Organ 1996; 74:439-43.

27. World Health Organization. World health report 2002: reducing risks, promoting healthy life. Geneva: World Health Organization; 2002.
28. Muening P. Cost-effectiveness analysis in health, a practical approach. 2nd Ed. San Francisco: JosseyBass; 2008.

29. Willan AR, Briggs A. Statistical analysis of cost-effectiveness data. New Jersey: Wiley and Sons; 2006.

30. Yadón ZE, Quigley MA, Davies CR, Rodrigues LC, Segura EL. Assessment of leishmaniasis notification system in Santiago del Estero, Argentina, 1990-1993. Am J Trop Med Hyg 2001; 65:27-30.

31. Afenyadu GY, Agyepong IA, Barnish G, Adjei S. Improving access to early treatment of malaria: a trial with primary school teachers as care providers. Trop Med Int Health 2005; 10:1065-72.

32. Mondal D, Nasrin KN, Huda MM, Kabir M, Hossain MS, Kroeger A, et al. Enhanced case detection and improved diagnosis of PKDL in a Kala-azarendemic area of Bangladesh. PLoS Negl Trop Dis 2010; 4:e832.

33. Singh SP, Hirve S, Huda MM, Banjara MR, Kumar $\mathrm{N}$, Mondal D, et al. Options for active case detection of visceral leishmaniasis in endemic districts of India, Nepal and Bangladesh, comparing yield, feasibility and costs. PLoS Negl Trop Dis 2011; 5:e960.

34. Gürtler RE. Sustainability of vector control strategies in the Gran Chaco Region: current challenges and possible approaches. Mem Inst Oswaldo Cruz 2009; 104:52-9.

35. Diniz JL, Costa MO, Gonçalves DU. Mucocutaneous leishmaniasis: clinical markers in presumptive diagnosis. Braz J Otorhinolaryngol 2011; 77:380-4.

36. Salomon OD, Zaidenberg M, Burgos R, Heredia VI, Caropresi SL. American cutaneous leishmaniasis outbreak, Tartagal city, province of Salta, Argentina, 1993. Rev Inst Med Trop São Paulo 2001; 43:105-8.

37. Deps PD, Viana MC, Falqueto A, Dietze R. Avaliação comparativa da eficácia e toxicidade do antimoniato de N-metil-glucamina e do estibogluconato de sódio BP88® no tratamento da leishmaniose cutânea localizada. Rev Soc Bras Med Trop 2000; 33:535-43.

38. Passos VM, Barreto SM, Romanha AJ, Krettli AU, Volpini AC, Gontijo CM, et al. Leishmaniose tegumentar na Região Metropolitana de Belo Horizonte: aspectos clínicos, laboratoriais, terapêuticos e evolutivos (1989-1995). Rev Soc Bras Med Trop 2001; 34:5-12.

39. Paula CD, Sampaio JH, Cardoso DR, Sampaio RN. Estudo comparativo da eficácia de isotionato de pentamidina administrada em três doses durante uma semana e de N-metil-glucamina 20mgSbV/ $\mathrm{kg} /$ dia durante 20 dias para o tratamento da forma cutánea da leishmaniose tegumentar americana. Rev Soc Bras Med Trop 2003; 36:365-71.

40. Oliveira-Neto MP, Mattos MS. An alternative antimonial schedule to be used in cutaneous leishmaniasis when high doses of antimony are undesirable. Rev Soc Bras Med Trop 2006; 39:323-6. 
41. Krolewiecki AJ, Romero HD, Cajal SP, Abraham D, Mimori T, Matsumoto T, et al. A randomized clinical trial comparing oral azithromycin and meglumine antimoniate for the treatment of American cutaneous leishmaniasis caused by Leishmania (Viannia) braziliensis. Am J Trop Med Hyg 2007; 77:640-6.

42. Teixeira AC, Paes MG, Guerra JO, Prata A, SilvaVergara ML. Failure of both azithromycin and antimony to treat cutaneous leishmaniasis in Manaus, AM, Brazil. Rev Inst Med Trop São Paulo 2008; 50:157-60.

43. Nilforoushzadeh MA, Jaffary F, Ansari N, Siadat AH, Nilforoushan Z, Firouz A. A comparative study between the efficacy of systemic meglumine antimoniate therapy with standard or low dose plus oral omeprazole in the treatment of cutaneous leishmaniasis. J Vector Borne Dis 2008; 45:287-91.

44. Zajtchuk JT, Casler JD, Martins Netto E, Grogl M, Neafie RC, Hessel CR, et al. Mucosal leishmaniasis in Brazil. Laryngoscope 1989; 99:925-39.

45. Martins Netto E, Marsden PD, Llanos-Cuentas EA, Costa JM, Cuba CC, Barreto AC, et al. Long-term follow-up of patients with Leishmania (Viannia) braziliensis infection and treated with glucantime. Trans R Soc Trop Med Hyg 1990; 84:367-70.
46. Oliveira-Neto MP, Mattos M, Pirmez C, Fernandes O, Gonçalves-Costa SC, Souza CF, et al. Mucosal leishmaniasis ("espundia") responsive to low dose of N-methyl glucamine (glucantime) in Rio de Janeiro, Brazil. Rev Inst Med Trop São Paulo 2000; 42:321-5.

47. Dedet JP, Melogno R, Cardenas F, Valda L, David C, FernandezV, et al. Rural campaign to diagnose and treat mucocutaneous leishmaniasis in Bolivia. Bull World Health Organ 1995; 73:339-45.

48. Valda Rodriguez L, Dedet JP, Paredes V, Mendoza C, Cardenas F. A randomized trial of amphotericin $\mathrm{B}$ alone or in combination with itraconazole in the treatment of mucocutaneous leishmaniasis. Mem Inst Oswaldo Cruz 1995; 90:525-8.

49. Reyburn H, Ashford R, Mohsen M, Hewitt S, Rowland M. A randomized controlled trial of insecticide-treated bednets and chaddars or top sheets, and residual spraying of interior rooms for the prevention of cutaneous leishmaniasis in Kabul, Afghanistan. Trans R Soc Trop Med Hyg 2000; 94: 361-6.

Submitted on 30/Nov/2012

Final version resubmitted on 19/Apr/2013

Approved on 12/Jul/2013 